\title{
Peakflow responses to forest practices in the western cascades of Oregon, USA
}

\author{
R.L. Beschta M.R. Pyles, A.E. Skaugset, C.G. Surfleet
}

\begin{abstract}
The effects of clearcut silviculture (road building, clearfelling, cable logging, and site preparation) were evaluated using long-term peakflow records for three small watersheds (60-101 ha) and six large basins (62-640 $\left.\mathrm{km}^{2}\right)$ in the western Cascades of Oregon, USA. After a calibration period, two of the small watersheds were treated while the third remained untreated (control). Analysis indicated that peakflow increases following treatments were dependent upon peakflow magnitude. Peakflow increases averaged approximately $13-16 \%$ after treatment for 1-yr recurrence interval events, and 6-9\% for 5-yr recurrence interval events. For the six large basins, multiple linear regression analyses of peakflows relative to: (1) peakflow magnitude; and (2) difference in percent area harvested provided mixed results. While significant $(p<0.05)$ relationships were found in half of the analyses, the explained variance $\left(\Delta r^{2}\right)$ due to harvesting was generally small $(1-7 \%)$.
\end{abstract}

\section{Introduction}

Study of the influences of forest management on peakflows in the Cascade mountains of western Oregon dates back to the early 1950s when a series of paired small watershed studies began in the H.J. Andrews Experimental Forest, east of Eugene, Oregon (Rothacher et al. 1967). Similar studies were initiated in the Fox Creek Watershed east of Portland, Oregon and the Coyote Creek Watershed, east of Roseburg, Oregon. A variety of experimental treatments ranging from only roading to complete clearfelling were used. Early reports of these studies by
Rothacher (1973), Harr et al. (1979), Harr and McCorison (1979), Harr (1980), and Harr et al. (1982) were limited in scope because of short posttreatment measurement periods. Until recently (i.e. Jones and Grant, 1996; Thomas and Megahan, 1998), the most extensive post-treatment data set was from the H.J. Andrews Watersheds 1 and 3 and reported on five years of post-treatment data (Rothacher, 1973). The different periods of time reported in the various studies, coupled with the opportunity for a single uncommon event (either a very large peakflow or a year with unusually small peaks) that could skew results, creates the need to carefully review the interpretations from the original studies. Table 1 summarizes the results from Cascade Range paired watershed studies with regard to peakflows. Since markedly different results were reported for annual and larger peakflows, as contrasted with 


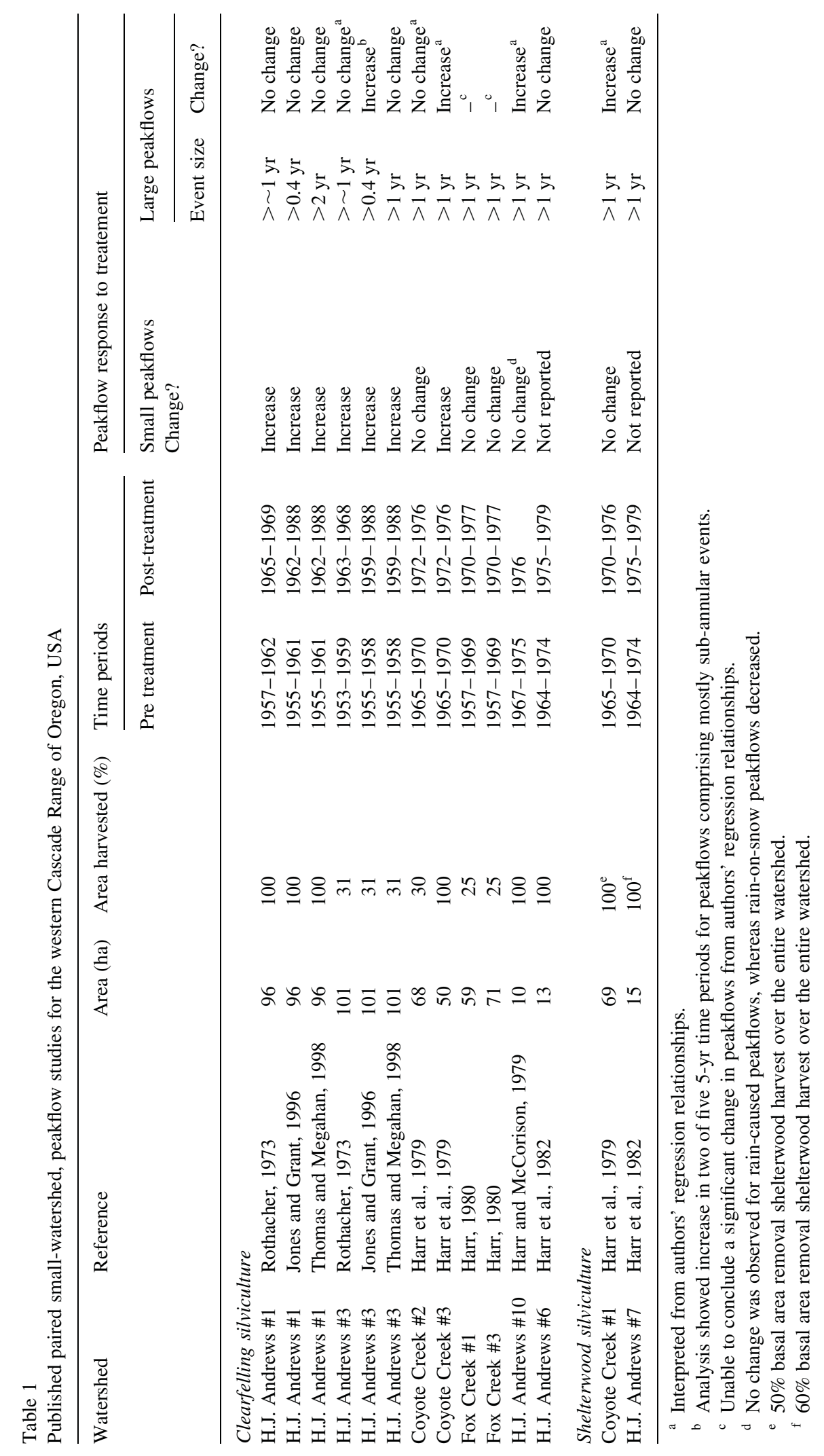


sub-annular peakflows, we have included both results in Table 1. In some cases, the direct reporting of large versus small peakflows was included in the original publications. In other cases, interpretation of the published results was necessary.

There are many features of the original studies that contribute to the variation in observations presented in Table 1. The objectives of the studies were not the same, hence both the characteristics of the data sets and the methods of analysis varied from study to study. For example, Harr and McCorison (1979) specifically separated rain from rain-on-snow peaks in their one-year study of H.J. Andrews Watershed 10. Jones and Grant (1996) separated events by season (fall, winter, spring), which generally correlates with rain versus rain-on-snow, but did not include large versus small peaks in these categories. Hence their large versus small peakflow results include both types of events. For some studies, interpretation of the original report is necessary to reach a conclusion on peakflow change. The Coyote Creek report (Harr et al., 1979) does not differentiate large and small peakflows, but large versus small peakflow effects can be interpreted from their regression relationships. The research and the results reviewed in Table 1 summarize a complex picture, hence the reader is encouraged to consult the original articles for a full understanding of the work. A review of Table 1 indicates that the majority of published peakflow research from the Oregon Cascades does not show increases in large peakflows (albeit with a varying definition of "large"), yet there is variation in the results.

Interest in the long-term response of peakflows in paired small watershed studies, as well as large basins by Jones and Grant (1996) and Thomas and Megahan (1998), presented an opportunity to evaluate relatively long-term records and analysis results from the H.J.
Andrews Watersheds 1 and 3, and, three pairs of large basins in the Cascade Range of western Oregon. The H.J. Andrews Watershed 1 and 3 results from the beginning of treatment through the 1988 water year (27 yr on Watershed 1 and $30 \mathrm{yr}$ on Watershed 3) are reported in Table 1. The large basin records used by Jones and Grant (1996), Thomas and Megahan (1998) covered periods ranging from 33 to $55 \mathrm{yr}$.

\subsection{Small water}

The H.J. Andrews Watershed 1 and 3 studies are classic paired watershed studies where Watershed 2 (60 ha), located geographically between Watersheds 1 and 3, was maintained as an unmanaged (unharvested) control throughout the study. Watershed 1 (96 ha) was clearfelled, cable yarded from the watershed divide, and broadcast burned prior to reforestation; no roads were constructed within the watershed. Watershed 3 (101 ha) had roads constructed (occupying approximately $6 \%$ of the watershed area), followed several years later by clearfelling, cable yarding, and broadcast burning of three harvest units. Approximately $31 \%$ of Watershed 3 was directly affected by road building and harvesting.

\subsection{Large basin}

The large basin data sets developed by Jones and Grant (1996), and used by Thomas and Megahan (1998), are based on timber sale records and GIS data bases for the proportion of basin area that was harvested at any given time, and US Geological Survey (USGS) stream gauge records for peakflows. Further detail on harvest histories can be found in Jones and Grant (1996) for the three pairs of basins listed in Table 2. Jones and Grant used percen feren in lan $r$ har as a variable to address the

Table 2

Availability of large basin streamflow data for the western Cascades of Oregon

\begin{tabular}{lccc}
\hline Basin pair & Basin area $\left(\mathrm{km}^{2}\right)$ & $\begin{array}{l}\text { Time period available } \\
\text { for analysis }\end{array}$ & $\begin{array}{l}\text { Time period used for } \\
\text { this analysis }\end{array}$ \\
\hline Upper Blue River & 119 & $1949-1991$ & $1964-1991$ \\
Lookout Creek & 62 & $1935-1990$ & $1935-1990$ \\
Salmon Creek & 313 & $1932-1987$ & $1932-1987$ \\
N. Fork of the Middle Fork of the Willamette R. & 637 & & \\
Breitenbush River & 280 & 559 & \\
North Santiam River & & \\
\hline
\end{tabular}


absence of a control basin for the large basin pairs. Percent difference in land area harvested is a potentially weak treatment variable because it is not unique, i.e. a $2 \%$ difference can be attained from an infinite number of spatially and temporally distributed combinations of harvest units between any two basins. However, a difference variable may represent the best chance for testing peakflow response hypotheses given the lack of controlled experiments at the scale of large basins.

\section{Study objectives}

The small watershed studies of Jones and Grant (1996), Thomas and Megahan (1998) are dominated by a population of sub-annular peakflows (i.e. peakflows with recurrence intervals of less than one year) that were earlier recognized (Rothacher, 1973) to behave statistically different than annual and larger peakflows. Both Jones and Grant and Thomas and Megahan address peakflow magnitude, but large peaks are not the focus of their studies. Further, the large watershed work of Jones and Grant (1996), Thomas and Megahan (1998) does not address the large watershed data using a model consistent with the findings from the small watershed analysis.

In this paper, we chronicle an analysis of data from the H.J. Andrews Watersheds 1 and 3 and the same large watershed pairs studied by Jones and Grant, and Thomas and Megahan, that will include: (1) a discussion of the large peakflows that we believe are of interest to forest land managers; (2) a discussion and treatment of peakflow data that addresses data quality; (3) an alternate analysis of large peakflows from the small watersheds; (4) an analysis of the large watershed peakflows that follows from the results of the small watershed studies; and (5) a discussion of our results in relation to those of Jones and Grant, and Thomas and Megahan.

\section{Peakflows}

The terms "peakflows" and "peak discharges" have been used variously in forest and range hydrology (Branson et al., 1981; Brooks et al., 1991), engineering (Dalrymple 1953), and geomorphology (Leopold et al., 1964). Peakflows with recurrence intervals greater than one year are important to fluvial processes and channel morphology. For example, "bankfull" flows in floodplain systems are associated with recurrence intervals in a range of 1- to 2-yr (Leopold et al., 1964; Richards, 1982). In mountainous terrain, studies in New Zealand found bankfull flow recurrence intervals ranged from 1- to $10-\mathrm{yr}$ (Mosley, 1981); in northern California, bankfull flows were associated with recurrence intervals of 11- to 100-yr (Nolan et al., 1987). Peakflows related to significant flooding are usually associated with events that have return periods of much greater than one year (Ziemer, 1998).

The flow that carries most of a stream's sediment, or "dominant discharge", is identified as the crest of a curve that results from a combination of frequency and magnitude relationships (Richards, 1982). While the dominant discharge of suspended sediment transport typical of floodplain streams may be associated with recurrence intervals of 1 - to 2 -yr, for mountain streams, larger flows may assume a more important role. For example, $36 \%$ of the total suspended sediment yield from a 15-yr period for a forested watershed in the Oregon Coast Range occurred during six days from two relatively large peakflows (Beschta, 1978). With regard to bedload sediment transport, recurrence intervals associated with dominant discharges are generally much larger than for suspended load (Richards, 1982). In a study of three small watersheds in the Oregon Cascades, where main channel gradients average approximately $25-40 \%$, Grant and Wolff (1990) found that the highest annual sediment production coincided with periods of mass soil movement. From one watershed, an estimated $85 \%$ of the total sediment yield over a 31-yr period occurred during debris flows from a single storm in 1964. Grant and Wolff concluded that the sediment yield histories from the three watersheds "...underscore the importance of episodic mass movements as controls on timing and magnitude of sediment yield from these steep, mountain watersheds." Clearly, relatively large and infrequent storms have a significant role in the morphology of Oregon's mountain stream channels and watershed sediment yields.

Important management considerations are associated with large peakflows in forested terrain. Oregon and Washington forest practices rules (Oregon Department of Forestry, 1994; Washington Forest 
Practices Board, 1995) require foresters and forest engineers to size culverts and other road drainage structures with sufficient capacity to convey at least a 50-yr recurrence interval flow. Thus, if forest practices are increasing the magnitude of relatively large peakflows (i.e. those with recurrence intervals of $50 \mathrm{yr}$ or larger) from small or large watersheds, it may be necessary to increase the flow capacities of road drainage systems. It should be noted that if such increases actually have occurred with historical forest practices, the effects are implicit in USGS flow records from which frequency analyses have been developed to assist in the sizing of drainage structures. From a variety of perspectives, floods, bankfull discharge, dominant discharge, sediment transport, channel morphology, and the design of road drainage structures, the scientific literature and regulatory setting are consistent in emphasizing the importance of peakflows with recurrence intervals of at least one year, and often much greater.

In their analysis of peakflow data from Watersheds 1 and 3 at the H.J. Andrews Experimental Forest, Jones and Grant (1996) selected the uppermost quartile of hydrograph peaks from the long-term flow records to represent "large event" peakflows. Since these flows corresponded to a recurrence interval of $0.4 \mathrm{yr}$, the majority of the "large event" peakflows are much smaller than those commonly associated with bankfull flow, dominant discharge, significant suspended and bedload sediment transport, landslide occurrence, or the design of road drainage structures. Only $40-45 \%$ of peakflows within the "large events" category for Watershed 1 and 3 analyses had recurrence intervals of greater than one year. However, in order to allow more direct comparison of the results of our analysis with both Jones and Grant (1996) and Thomas and Megahan (1998), a recurrence interval of $0.4 \mathrm{yr}$ was retained for our analysis of large events. For the large basins, peakflows generally consisted of partial duration series flood peaks (i.e. 1-yr events) from USGS stream gauge records.

\section{Data quality}

The hydrologic data that we began with for both the small watershed and large basin analyses was provided by Jones and Grant, however we ultimately included additional data not used in their work. For the small watersheds, we selected the entire set of pretreatment data beginning in 1953 for our analysis of comparative watershed peakflow response on the small watersheds. This added nine peakflow pairs to each of the watershed data sets; a $45 \%$ increase to the Watershed 1 calibration data set and a $56 \%$ increase to the Watershed 3 calibration data set utilized by Jones and Grant (1996). The small watershed data included only peakflows and does not include any percentage of basin harvested over time, since the experimental treatment consisted of fixed percentages of the watersheds modified by roads and/or clearcut harvesting. The large basin data consisted of peakflows and percentages of the basin areas that were harvested over time. We considered three issues of data quality to assist in reducing the raw peakflow data to the final data that was used for analysis and interpretation of results.

\subsection{Accuracy of individual peakflow measuremen}

Weirs or flumes produce the most accurate discharge measurements. However, even carefully designed and installed flumes, such as those used on the H.J. Andrews Watersheds 1, 2, and 3, produce discharge values with an accuracy of $\pm 3-5 \%$ (interpreted from Blaisdell, 1944; Herschy and Fairbridge, 1998). If flume calibration is done with a current meter or similar device rather than a weighing basin, an additional error and a systematic calibration bias is a likely result (Blaisdell, 1944). Hence, detecting a treatment effect of less than approximately $3-5 \%$ in these situations will likely be extremely difficult.

Various flume and recording equipment malfunctions are expected at any streamflow measuring station. When a malfunction occurs during a peakflow event, it is common practice to estimate the peakflow. Some of the small watershed peakflows in the raw data set consisted of "estimated" values. We consider the use of estimated peakflows to be inappropriate because: (1) the basis for the estimation procedure was not known; and (2) the estimation procedure would be unlikely to replicate the mean and variance of direct measurements; therefore, we excluded estimated events from our analysis. For the 1953-1988 
period, this resulted in the removal of four data pairs from Watershed 1 and 2 comparisons and eight data pairs from Watershed 3 and 2 comparisons.

The use of USGS gauge data for the large watersheds presents additional data accuracy and flow estimate concerns. Even in the best circumstances, stream gauge data are subject to larger errors in measurement of peak discharge than either weir or flume data typical of experimental watersheds. The primary source of error is continual and/or aperiodic change in the control section during high flows and an associated shift in the rating curve. For example, the rating curve for the North Fork of the Middle Fork of the Willamette River, which is included in the period of record for the large basin peakflow data, changed by approximately 20\% during the 1964 flood. While the USGS constantly tracks these changes for currently maintained gauges, these efforts serve only to keep the gauge to within an accuracy of about plus or minus $10 \%$. Gauge malfunctions are again resolved by professional estimation of missing peakflows by the USGS and are a valuable addition to the longterm record. However, for hydrologic analyses trying to decipher possible peakflow changes associated with land use, we concluded it was necessary to exclude estimated data from our analysis. Two peakflow data pairs were removed from the Salmon Creek/North Fork of the Middle Fork of the Willamette River data set because they were estimated.

\subsection{Potential for bias}

Bias in the peakflow data for a particular watershed will exist if the stream gauge calibration systematically produces higher (or lower) than true peakflow values. While bias can also exist if there is a systematic change in peakflow calibration over time that is not corrected by regular re-calibration of the stream gauge, the presence of bias in a paired watershed study will not always invalidate the objectives of the study. For example, testing the "null hypothesis" that peakflows have not changed between the pretreatment and post-treatment periods is likely to produce correct results if both watersheds had constant (but not necessarily equal) calibration biases in their respective stream gauge calibrations. However, attempts to quantify a treatment effect, if present, will likely produce incorrect results since the gauge calibration biases can affect the absolute values of peakflows, and therefore any estimate of the treatment effect. This different effect on different potential objectives of a peakflow study must be carefully considered when drawing conclusions from study results.

Examples of other factors that can introduce bias into a peakflow study are: (1) temporal climate trends during the data collection period; (2) recovery of the treatment effect to pretreatment levels in the case of vegetation related effects; (3) alteration of the control section hydraulics over time (e.g. entrance conditions may continue to adjust over time because of local scour and fill of the streambed, the surface roughness of concrete flumes tends to increase over time); and (4) systematic change in confounding variables that were not considered in the experimental design. This last effect turns out to be of significant concern with one of the available large basin pairs evaluated in this study.

A problematic aspect of using USGS gauge data for comparative peakflow analysis is that they are occasionally moved because of shifting control sections or the proximity of a gauge to a new or existing water diversion. During the period of record selected by Jones and Grant (1996), two of six large-basin gauges were moved. The North Santiam River gauge was moved in 1952, reducing the contributing basin area by $4 \%$. The Blue River gauge was moved prior to the beginning of the 1964 water year, coincident with the construction of Blue River Dam. At its original location, the Blue River watershed area was $64 \%$ larger than its current location upstream of the confluence of Lookout Creek and Blue River. To use the complete gage record, peak discharges that occurred before the gauge was moved must be adjusted to reflect the latter gauge location (or vice versa). We attempted to identify a gauge adjustment factor based on unit area discharge from gauges in the same region of the Cascade mountains. No systematic relationship between unit area discharge and watershed area or other variables could be found. This is evident in the wide range in the 1-yr peak discharge per unit area for the large basins reported by Jones and Grant (1996, Table 4). The 4\% change to the North Santiam drainage area may be small enough that serious errors are not introduced to the North Santiam data set by proportionately adjusting the record, but we believe that the same cannot be said for the Blue 
River gauge. Further, the fact that the Lookout Creek basin is located within the pre-1964 Blue River gauge basin means that the pre-1964 data pairs are not independent and, from a statistical perspective, should not be treated the same as the post-1963 data pairs. Hence, we concluded that only the post-1963 data can be used for analysis - this reduces the number of events in the Blue River/Lookout Creek data set by about half.

\subsection{Isolation of treatment}

This issue is not purely a data quality issue, but is in part an experimental design issue. The desire in any field experiment is to isolate treatment response by designing the experiment so that statistically significant results from data analysis can be interpreted as a treatment effect. In a paired watershed study, the quality of the pairing is an important experimental design factor. The H.J. Andrews Watersheds 1-3 are reasonably well matched (paired) in that they are side by side, share similar geology, and are of similar sizes.

The large basins (Table 2) were selected because of available USGS gauge records and thus the gauges were not originally installed as part of a planned experiment. As a result, basin areas, which are an artifact of gauge locations, are not well matched. For each of the three "pairs," one basin was approximately twice the size of the other (prior to 1964 the Blue River gauge basin was actually four times the size of the Lookout Creek basin). Further dissimilarities are apparent between pairs. For example, the estimated 1-yr recurrence interval for the larger basin of the Blue River/Lookout Creek pair and the Salmon Creek/North Fork of the Middle Fork Willamette pair has a larger discharge per unit area; the opposite is true for the Breitenbush River/North Santiam River pair (Jones and Grant, 1996, Table 4). Such differences are not unexpected from a group of gauged large basins even in the same region. Differences in basic characteristics (e.g. area-elevation relationships in relation to storm patterns) suggest an opportunity for differential hydrologic response with or without land management treatments. The potential for differential responses is a major reason for "quality pairing" in experimental watershed studies although, admittedly, such pairing may not always be achieved. In the case of the large-basin pairs, the opportunity for differential response to treatment is more problematic since the treatment variable, difference in percent harvested, is not unique, i.e. a $2 \%$ difference can be attained from essentially an infinite number of spatially and temporally distributed harvest combinations.

The size and adjacency of the small watershed pairs makes the assumption that peak discharges, which are coincident in time, are the result of nearly identical storm inputs to the watersheds reasonable. This similarity of storm input to basin pairs is an important concern since it is a change in the response due to treatment that we wish to test, not a difference in storm input. Variations in storm characteristics (e.g. amounts, timing, precipitation form, and distribution) can create different hydrologic responses that are not associated with land treatments, but instead simply the result of different storm inputs across each basin. The potential for time-coincident peaks to behave differently because of different storm patterns increases significantly as basin size increases. For example, rainfall data from the Oregon Coast Range (Surfleet, 1997) indicates that single storm rainfall amounts vary by as much as $50 \%$ between adjacent basins of a size similar to those of the large-basins used in this analysis. While variability of storm precipitation (and rain-on-snow melt) in the Cascades may be less than the Coast Range, significant variability should be expected. Thus, any statistical relationship between a large-basin pair prior to and following the implementation of forest management practices is likely to be more variable than for the small watersheds. Without a period of pretreatment calibration it is not possible to determine the character of this variability, including the presence (or absence) of bias. While the

ference in percent area harve variable seems to provide a convenient representation of management in the large basin pairs, simply attributing any observed peakflow differences to management effects without recognizing these other concerns is a major challenge in developing meaningful conclusions.

\section{Analysis and results}

\subsection{Small water}

Our analytical approach used regression analysis (Hirsch et al., 1993). This is the same approach used 

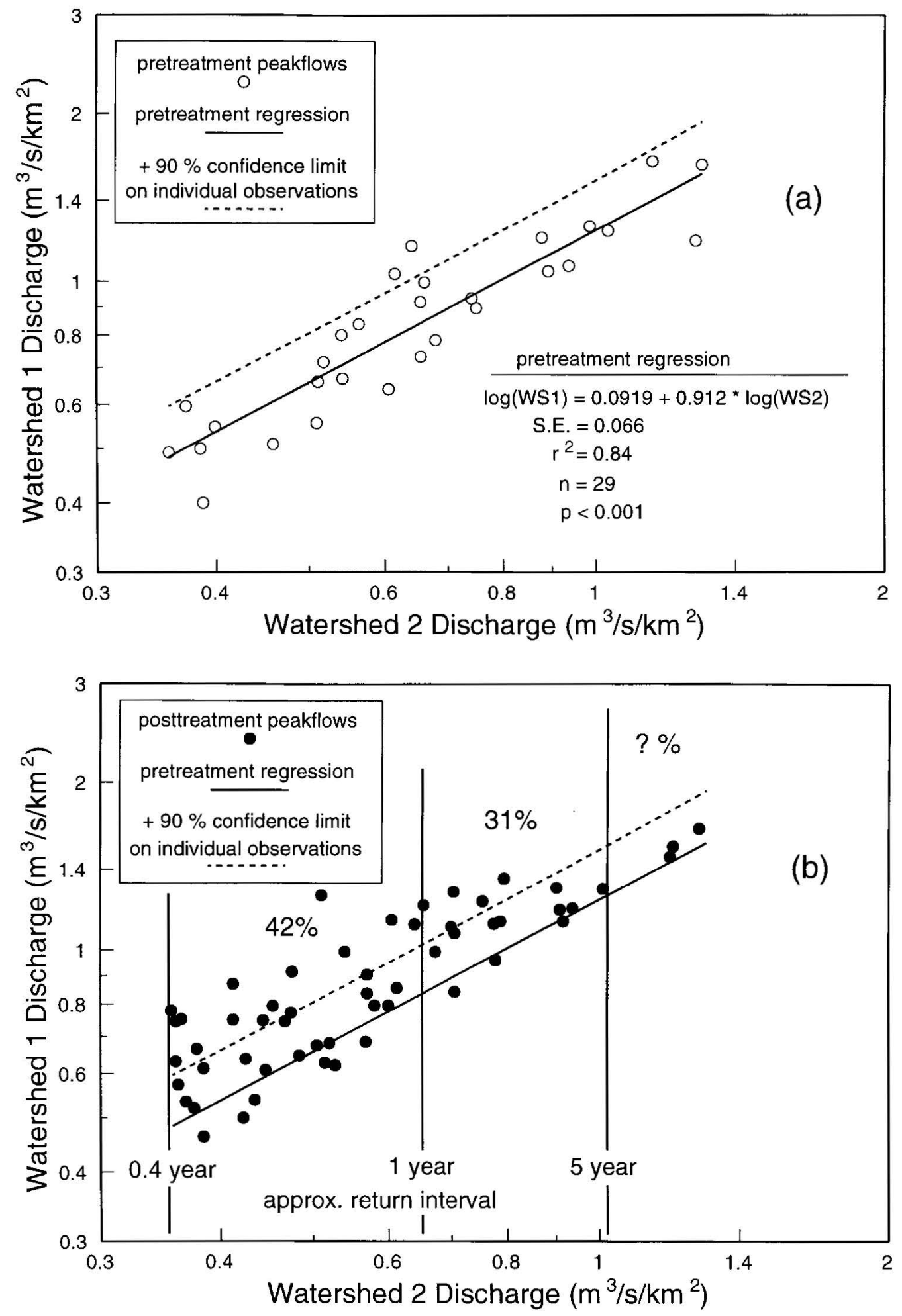

Fig. 1. 


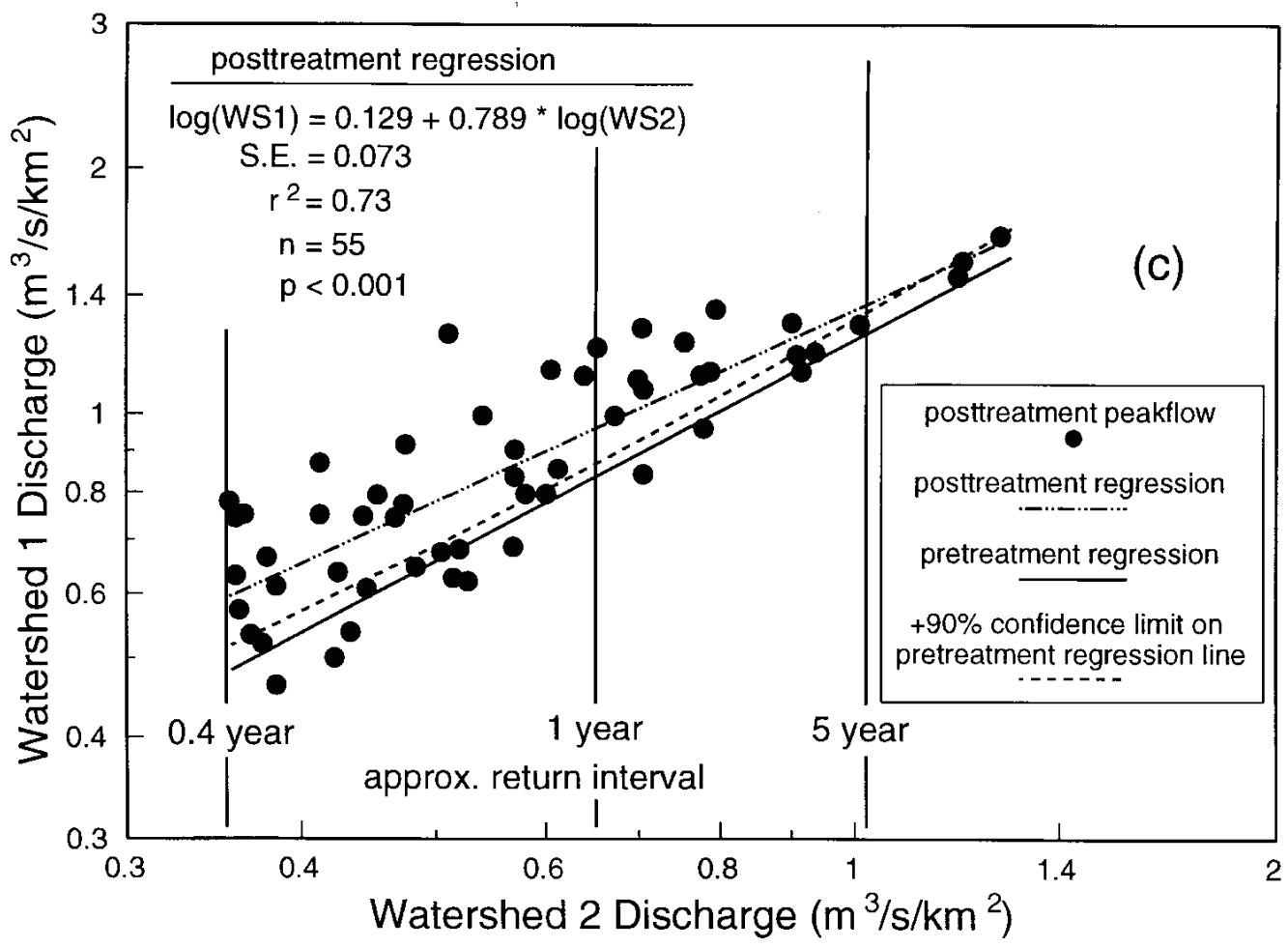

Fig. 1. (a) Pretreatment regression relationship of $\quad 0.4$-yr recurrence interval peakflows for Watersheds 1 and 2 with the upper $90 \%$ confidence limit on individual observations, (b) post-treatment (following harvesting and burning) peakflow responses of Watershed 1 (percentages indicate the proportion of Watershed 1 peakflows within a recurrence interval class that exceed the upper $90 \%$ confidence limit on individual observations), and (c) pretreatment and post-treatment (following harvesting and burning) regression relationships of 0.4-yr recurrence interval peakflows for Watersheds 1 and 2, with the upper 90\% confidence limit on the pretreatment regression. Data are from the H.J. Andrews Experimental Forest, western Cascades of Oregon, USA.

by Rothacher (1973) in the original analysis of the H.J. Andrews Watershed 1 and 3 peakflow data, with the exception that we used logarithmic transformations of the peakflows to eliminate heteroscedasticity.
Comparison of pretreatment and post-treatment regression equations presents a number of problems. First, standard statistical comparison of regression coefficients serves only to show that there either is

Table 3

Predicted peakflows from regression analysis of pretreatment and post-treatment "large events" (i.e. 0.4-yr recurrence interval) for Watersheds 1 and 3, H.J. Andrews Experimental Forest, western Cascades of Oregon, USA

\begin{tabular}{llll}
\hline $\begin{array}{l}\text { Recurrence } \\
\text { interval }(\mathrm{yr})\end{array}$ & $\begin{array}{l}\text { Predicted pretreatment } \\
\text { peakflow }\left(\mathrm{m}^{3} \mathrm{~s}^{-1} \mathrm{~km}^{-2}\right)\end{array}$ & $\begin{array}{l}\text { Predicted post-treatment } \\
\text { peakflow }\left(\mathrm{m}^{3} \mathrm{~s}^{-1} \mathrm{~km}^{-2}\right)\end{array}$ & $\begin{array}{l}\text { Increase due } \\
\text { to treatment }(\%)\end{array}$ \\
\hline Watershed 1 & & & 28 \\
0.4 & 0.47 & 0.6 & 16 \\
1 & 0.83 & 0.96 & 9 \\
5 & 1.4 & 1.53 & 24 \\
Watershed 3 & & & 13 \\
0.4 & 0.34 & 0.42 & 6 \\
1 & 0.6 & 0.68 & 6 \\
5 & 1.0 & 1.06 & \\
\hline
\end{tabular}



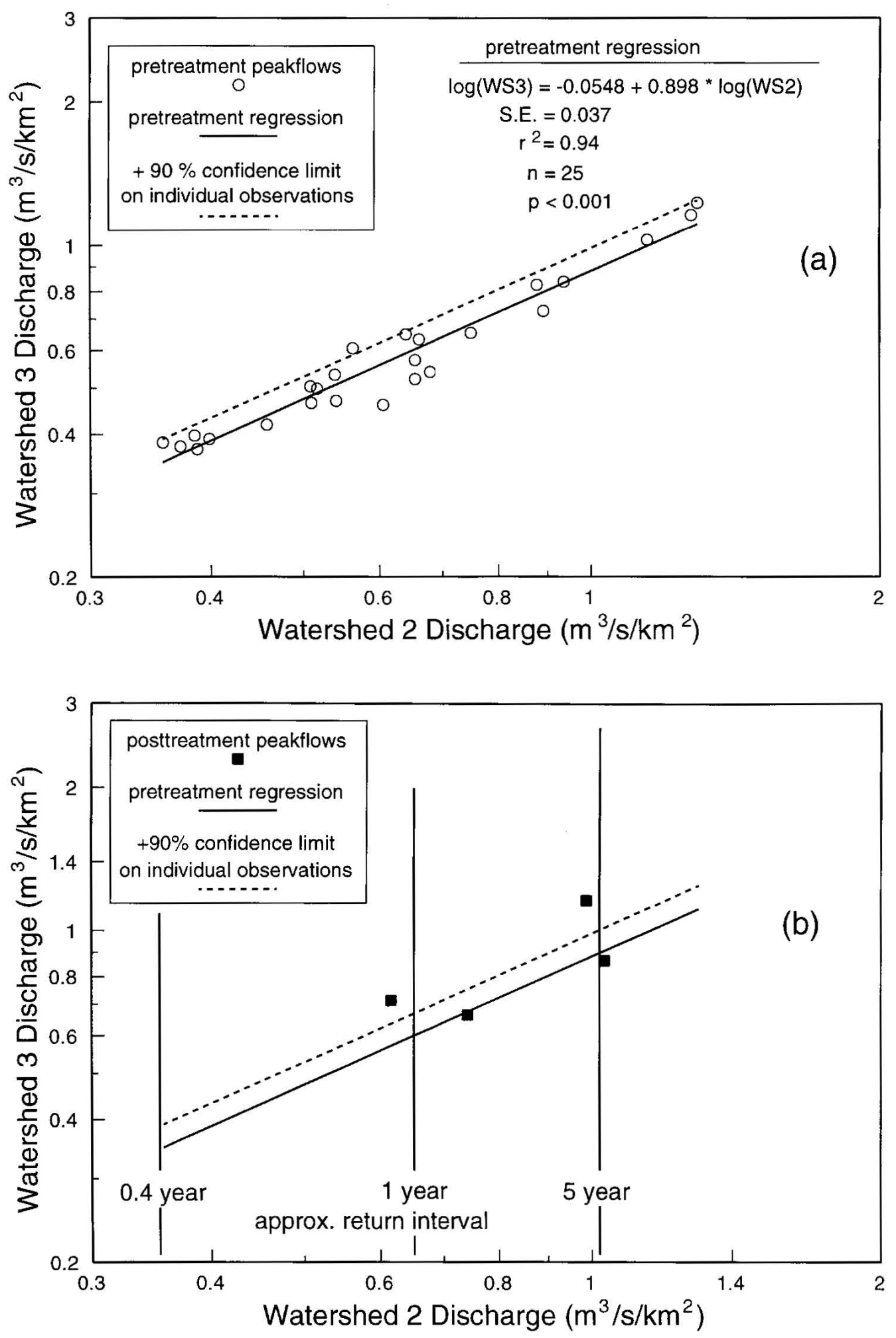

Fig. 2. 

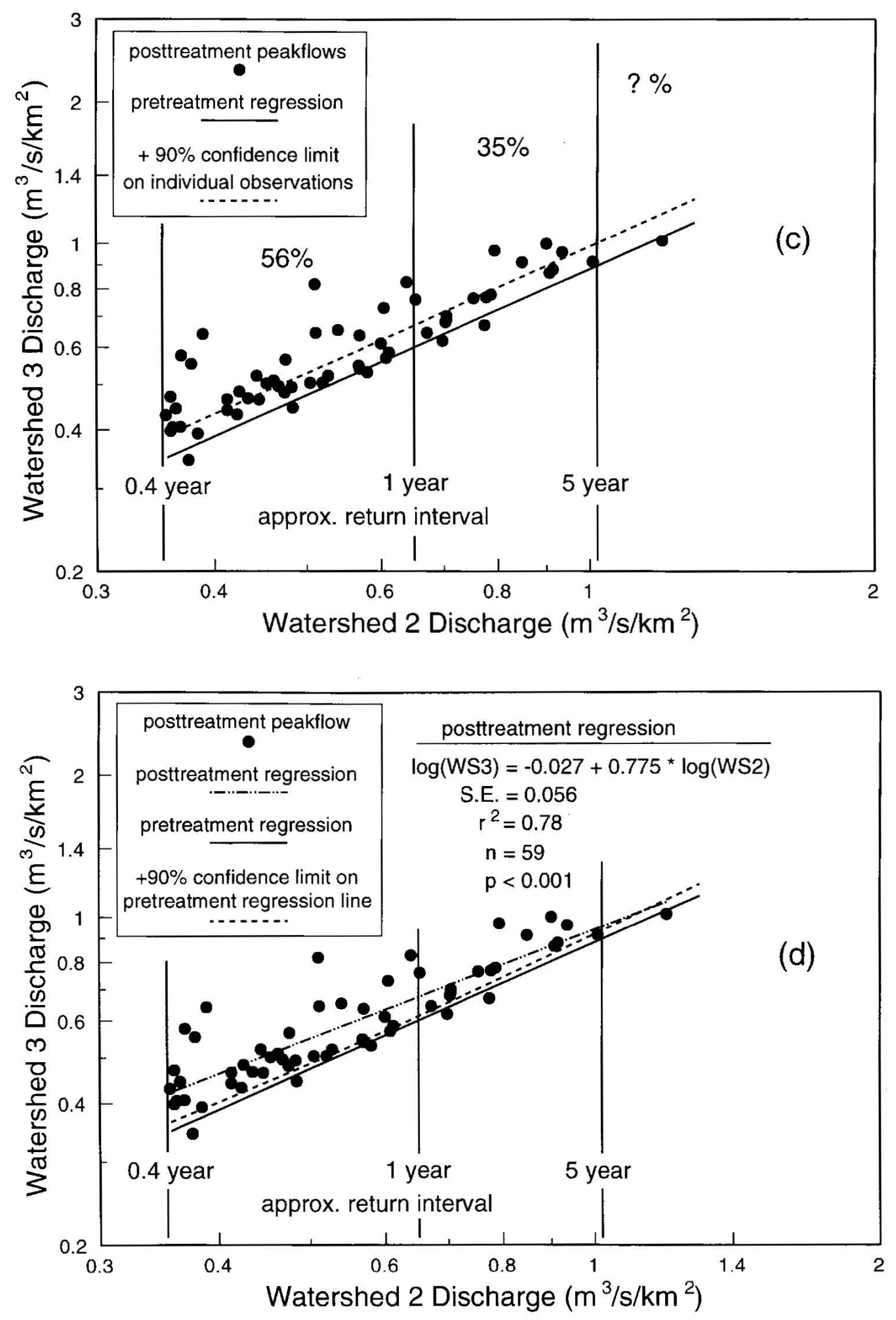

Fig. 2. 
or isn't a difference in each of the coefficients, not necessarily whether peakflows of a given magnitude have been increased or remain the same following treatment. Second, even the "large" peakflow data set that we examined was dominated by peakflows (0.4- to 1-yr return interval events) at the small end of the large peakflow scale, hence the expected result of an increase in smaller peakflows, which had been found in Rothacher's original analysis, would tend to increase the intercept of the post-treatment regression relationship relative to that of the pretreatment relationship. This situation is evident in the results of Thomas and Megahan (1998) for the entire H.J. Andrews Watershed 1 and 3 data sets.

Because we were concerned primarily with the possibility of a peakflow increase due to treatment, we established the upper $90 \%$ (one-tailed) confidence limit (CL) for single observations from the pretreatment regression as a basis for comparison (Fig. 1a), following an approach used by Beschta (1978). Thus, if no increase in peakflows occurred following a forest practice, $10 \%$ of the post-treatment peakflows, on average, would normally exceed the upper $90 \%$ CL. Fig. 1b shows the percentage of post-treatment peakflows from Watershed 1 that exceeded the upper $90 \%$ CL from the pretreatment watershed calibration period. Because of the limited number of peakflow observations comprising the "large event" data, we were only able to stratify the post-treatment data into three groups based on the magnitude of peakflow for Watershed 2 (the control); 0.4-yr to 1-yr return interval, 1-yr to 5-yr return interval, and 5-yr return interval. Clearly, the percentage of post-treatment peakflows greater than the pretreatment upper $90 \%$ CL decreases with increasing peakflow magnitude. However, definitive statements about the magnitude of the peakflow increase and return interval at which an increase is no longer present are hampered by data set size. In particular, the 5-yr return interval group contains only three observations.

Some indication that increases in peakflows above the 5-yr return interval are not present in the data set is visibly evident in Fig. 1b. A better, but still not statistically definitive representation of this pattern is illustrated in Fig. 1c which shows the pretreatment regression line, the upper $90 \%$ (one-tailed) confidence limit on that regression, and the post-treatment regression line. The post-treatment regression line enters the domain of the upper $90 \%$ confidence limit on the pretreatment regression line at a peakflow magnitude of about the 5-yr event. Both equations were used to determine average pretreatment and post-treatment flows for selected recurrence intervals, using procedures presented by Ferguson (1986). Results illustrate a decrease in average treatment response at higher recurrence intervals (Table 3). Whereas an average peakflow increase of $16 \%$ was associated with a 1-yr event for the clearfelled watershed, the increase drops to $9 \%$ for a 5-yr event. This trend of decreasing treatment response for larger recurrence interval events, as indicated by the regression lines in Fig. 1c, suggests that there was no significant treatment effect for relatively large events, i.e. those with recurrence intervals of approximately $5 \mathrm{yr}$ or greater. Even if a small treatment response actually occurred at these higher flows, the outcome would be essentially undetectable given the general inability of flumes to measure relatively large peakflows more precisely than within a few percent.

A similar analysis of the Watershed 3 data is presented in Fig. 2. However, the treatment sequence for Watershed 3 was more complicated than for Watershed 1. Following pretreatment calibration, road construction occurred. Several years later, a patch clearfelling and broadcast burning treatment was imposed. The peakflows from the road-only period for Watershed 3 are presented in Fig. 2b. However, because only four peakflows larger than the $0.4 \mathrm{yr}$ return interval occurred during the roadonly period, this data set is too limited for meaningful analysis of large peakflows. It should be noted that the road influence is implicitly included in

Fig. 2. (a) Pretreatment regression relationship of $\quad 0.4-y r$ recurrence interval peakflows for Watersheds 3 and 2 with the upper $90 \%$ confidence limit for individual observations, (b) post-treatment (following road building) peakflow responses of Watershed 3 with the upper $90 \%$ confidence limit on individual observations, (c) post-treatment (following road building, patch-cutting, and burning) peakflow responses of Watershed 3 (percentages indicate the proportion of Watershed 3 peakflows within a recurrence interval category that exceed the upper $90 \%$ confidence limit on individual observations), and (d) pretreatment and post-treatment (following road building, patch-cutting, and burning) regression relationships of $0.4-\mathrm{yr}$ recurrence interval peakflows for Watersheds 3 and 2, with the upper $90 \%$ confidence limit on the pretreatment regression. Data are from the H.J. Andrews Experimental Forest, western Cascades of Oregon, USA. 

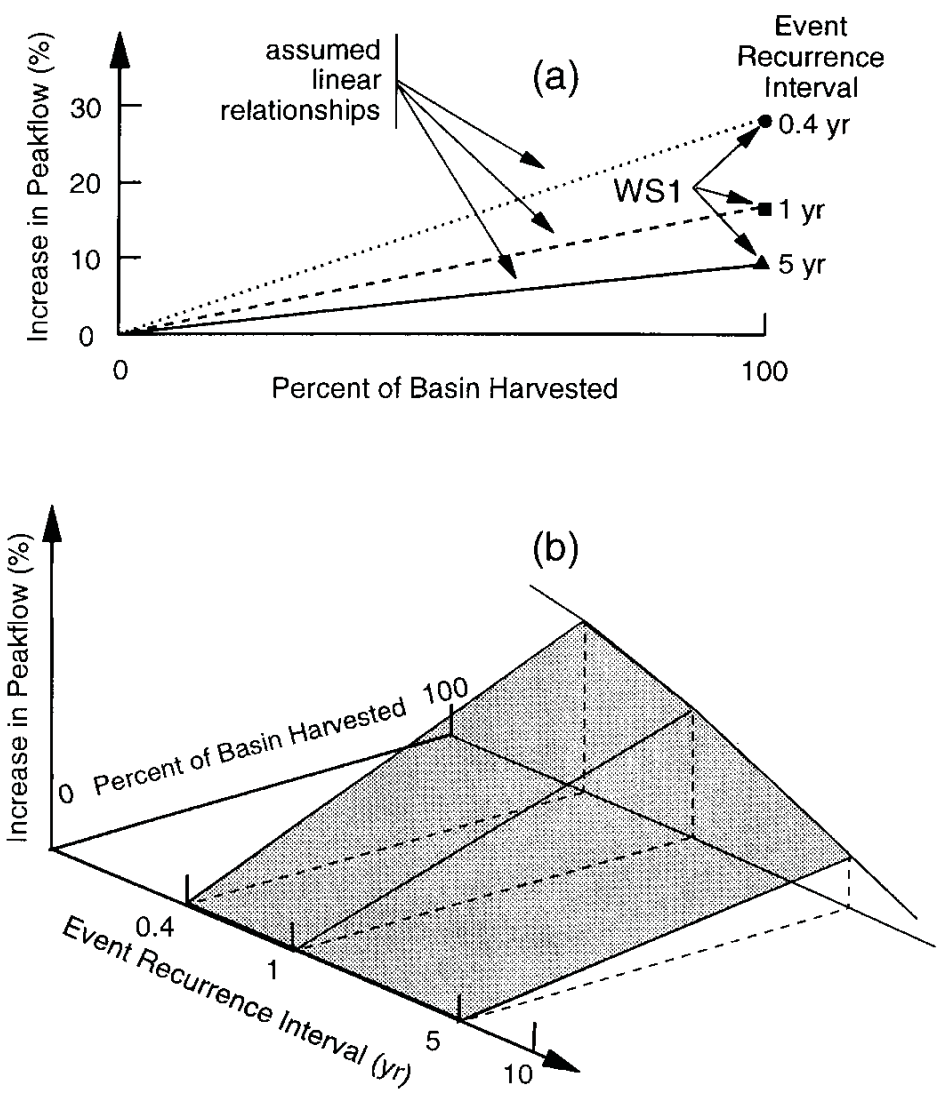

Fig. 3. (a) Peakflow response relative to percentage of basin harvested and event recurrence interval and (b) a three-dimensional representation of peakflow response relative to percentage of basin harvested and event recurrence interval (relationships are inferred from the results of small watershed analyses).

the post-harvesting peakflows presented in Fig. 2c and d. Similar to the results of Watershed 1, the regression lines illustrated in Fig. 2d approach a common domain for flows of approximately $1 \mathrm{~m}^{3} \mathrm{~s}^{-1} \mathrm{~km}^{-2}$ and larger, about the size of the 5-yr event. Whereas an average peakflow increase of $13 \%$ was found for a 1 -yr event (Table 3), the increase diminished to $6 \%$ for a $5-y r$ event. Again, given the uncertainties associated with measurement of instantaneous peakflows at the upper end of a rating curve, random variations in hydrologic conditions during a given storm, and inherent differences in the "paired" watersheds, these relationships indicate it is unlikely that treatment effects either occur or are discernible for peakflows with recurrence intervals of approximately $5 \mathrm{yr}$ or greater.

\subsection{Large basins}

The small watershed analyses presented herein indicates that forest management via the combination of road construction, timber harvesting, and site preparation (broadcast burning) can increase peakflows, with the greatest increases being observed for sub-annular peakflow events and either small or no increases for greater than 5-yr events. These results suggested a three-dimensional functional relationship in which the increase in peakflow is related to: (1) the proportion of watershed treated; and (2) the magnitude of the event. However, with regard to the proportion of watershed area harvested and peakflow increases we had only two experimental watersheds for establishing a relationship and thus, as a first-order approximation, we assumed a linear relationship between these two variables. Using results from the clearcut watershed (Watershed 1), the average peakflow increases form a family of lines by recurrence interval (Fig. 3a). If this family of lines is plotted in three dimensions, with axes as shown in Fig. 3b, a 
response surface results. While this response surface may be a reasonable representation of what the small watershed results suggest should occur for a large watershed, it is not a practical representation with regard to a large-basin data set because the "event recurrence interval" axis requires that the population of peakflows be constant. The ordinate in Fig. 3b represents the relative increase in peakflow as a result of forest practices and is the unknown that we are trying to determine. The difficulty in this formulation with regard to the large basins is that an untreated control watershed with an extended pretreatment period did not exist. In an attempt to address this difficulty, the response function illustrated in Fig. 3b was superimposed on a planar surface that relates the untreated peakflow from one watershed to the untreated peakflow of the other watershed, as shown by the shaded surface in Fig. 4. A multiple regression relationship that can describe the response surface illustrated in Fig. 4 was used to evaluate potential peakflow increases in the large basin data sets:

$\log _{10}\left(Q_{\mathrm{D}}\right)=\beta_{0}+\beta_{1} \log _{10}(Q)+\beta_{2} \frac{\text { area }}{Q}$

where $Q$ is the peakflow from "independent" basin; $Q_{\mathrm{D}}$ the peakflow from "dependent" basin; area the difference in percent of watershed area harvested (i.e. treatment); and $\beta_{0}, \beta_{1}, \beta_{2}$ are the regression coefficients.

In Eq. (1), the second regression term establishes the response surface describing the peakflow relationship between the two basins for a "no-treatment" condition, and the third term establishes the response to treatment. The third term is an interaction term because the effect of treatment is not constant with peakflow magnitude (Fig. 3). The manner in which the interaction term includes consideration of treatment and event magnitude is illustrated in Fig. 4, which shows the magnitude of the second and third terms in Eq. (1) plotted as a point on the "treatment/ $Q$ " plane that is described by the interaction term. Referring to Fig. 4, the interaction term is the slope of the vector from the origin to the point on the "treatment/ $Q$ " plane described by a particular data pair. The interaction term is not as robust as we might like since we do not know whether a constant value of the interaction term corresponds to a constant treatment effect, but the term does differentiate between areas of large treatment effect (near the "difference in percent basin area harvested" axis) and areas of small treatment effect (near the $Q$-axis). Further, the interaction term does not use the base 10 logarithm of the independent basin peakflow because of numerical difficulties with division by zero or the sign inversion produced by taking the logarithm of small values.

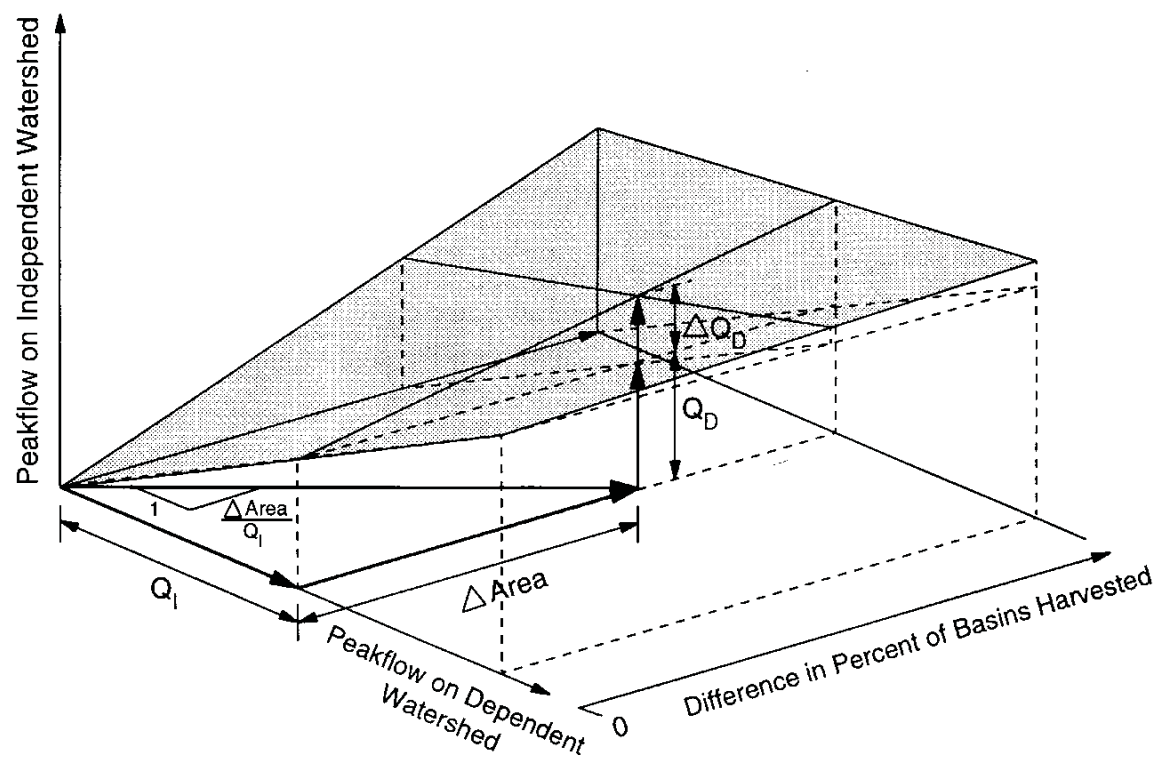

Fig. 4. Illustration of peakflow response surface superimposed on the untreated peakflow relationship between two watersheds. 
An additional point about Eq. (1) should be noted. The error term in the regression equation is expressed in the units of the dependent variable $\left(\log _{10} Q_{\mathrm{D}}\right)$ and graphically it occurs in the direction of the dependent variable axis. This means that treatment variable ( area) in the interaction term must only influence the dependent variable, and not the other independent variable $(Q)$. The treatment variable developed by Jones and Grant (1996) and defined as:

$$
\begin{aligned}
& \text { area } \quad(\% \text { dependent watershed harvested }) \\
& -(\% \text { independent watershed harvested })
\end{aligned}
$$

does not insure that the regression error terms are only in the dependent variable. A given increase in the area variable can occur from a range in absolute increases in the harvested area of the dependent watershed coupled with an increase in the harvested area of the independent watershed. Expected peakflow increases could then exist for both the dependent and independent watersheds, but by differing amounts. This behavior, which violates a basic assumption about the error term in a regression equation, can be either ignored, or limited. Analysis of the full large basin data sets ignores this behavior while dividing the data so that only positive area terms are used in each regression limits the influence of the behavior. We examined the large basin pair data both ways. Each basin pair yields, two regression equations, as the role of the independent and dependent watersheds are switched.

Results (Table 4) indicate that the treatment variable was statistically significant in only half of the regression relationships and one of the six significant treatment regression coefficients ( 2 ) was negative, which would indicate peakflow decreases with harvesting rather than the hypothesized increase. Further, three of the six significant treatment regression coefficients explained less than one percent of the variation in the dependent variable (i.e. the logarithm of peakflow on the dependent watershed).

\section{Discussion}

A broad look at our analysis of peakflows, and that

Table 4

Results of multiple regression, based on the form of Eq. (1) (in the case where regression coefficients were not significant at $P<0.05$, the coefficients presented are for a reduced regression model that does not contain the coefficient) for peakflows from large basins in the western

\begin{tabular}{|c|c|c|c|c|c|c|c|c|c|c|}
\hline$Q_{\text {dependent }}$ & $Q_{\text {independent }}$ & o & & 1 & 2 & & $r^{2}$ & $\left(r^{2}\right)_{2}^{a}$ & S.E. & $n$ \\
\hline \multicolumn{11}{|c|}{ Regression using only positive values of treatment variable } \\
\hline Lookout Creek & Blue River & -0.218 & & 1.25 & 0.0119 & & 0.80 & 0.07 & 0.10 & 57 \\
\hline Blue River & Lookout Creek & 0.079 & & 0.641 & $\mathrm{~S}^{\mathrm{b}} ; P$ & 0.66 & 0.71 & - & 0.06 & 30 \\
\hline Breitenbush River & North Fork, Santiam River & 0.116 & & 0.793 & $\mathrm{~S} ; \quad P$ & 0.40 & 0.70 & - & 0.11 & 169 \\
\hline North Fork, Santiam River & Breitenbush River & -0.281 & & 0.779 & $\mathrm{~S} ; P$ & 0.56 & 0.77 & - & 0.08 & 23 \\
\hline Salmon Creek & $\begin{array}{l}\text { N. Fork, M. Fork, } \\
\text { Willamette River }\end{array}$ & $\mathrm{NS} ; P$ & 0.07 & 1.082 & 0.0052 & & 0.76 & $<0.01$ & 0.09 & $98^{\mathrm{c}}$ \\
\hline $\begin{array}{l}\text { N. Fork, M. Fork, } \\
\text { Willamette River }\end{array}$ & Salmon Creek & NS; $P$ & 0.22 & 0.909 & $\mathrm{~S} ; \quad P$ & 0.86 & 0.86 & - & 0.07 & $89^{c}$ \\
\hline \multicolumn{11}{|c|}{ Regression using both positive and negative values of } \\
\hline Lookout Creek & Blue River & -0.162 & & 1.16 & 0.0064 & & 0.77 & 0.05 & 0.10 & 87 \\
\hline Blue River & Lookout Creek & 0.0785 & & 0.651 & 0.0034 & & 0.76 & 0.04 & 0.08 & 87 \\
\hline Breitenbush River & North Fork, Santiam River & 0.123 & & 0.815 & $\mathrm{~S} ; \quad P$ & 0.62 & 0.70 & - & 0.10 & 192 \\
\hline North Fork, Santiam River & Breitenbush River & -0.273 & & 0.861 & $\mathrm{~S} ; \quad P$ & 0.62 & 0.70 & - & 0.11 & 192 \\
\hline Salmon Creek & $\begin{array}{l}\text { N. Fork, M. Fork, } \\
\text { Willamette River }\end{array}$ & -0.046 & & 0.998 & 0.0039 & & 0.82 & $<0.01$ & 0.09 & 169 \\
\hline $\begin{array}{l}\text { N. Fork, M. Fork, } \\
\text { Willamette River }\end{array}$ & Salmon Creek & -0.069 & & 0.828 & -0.0022 & & 0.82 & $<0.01$ & 0.08 & 169 \\
\hline
\end{tabular}
Cascades of Oregon, USA

${ }^{\text {a }}$ Increase in $r^{2}$ as a result of including ${ }_{2}$ in the regression equation.

${ }^{b}$ NS not significant.

c " 0 " (zero) values of the treatment variable were used in both regressions for this basin pair. 
of Jones and Grant (1996) and Thomas and Megahan (1998) shows that each of the methods has strengths and weaknesses. Perhaps the principal weakness in our small watershed analysis is that a peakflow event that occurs in response to a given rainfall event shortly after treatment is weighted the same as a peakflow event that occurs in response to an identical rainfall event $20 \mathrm{yr}$ later. Yet, we know that hydrologic responses of a watershed following a treatment tend to decay over time (e.g. Hicks et al., 1991)—a "new" treatment (young, growing forest) replaces the initial treatment (clearfelling). Quite simply, we do not have a constant post-treatment population over time from which to sample peakflows. Jones and Grant (1996), Thomas and Megahan (1998) attempted to overcome this problem by subdividing the posttreatment analysis into 5-yr periods. While this subdivision of the data set potentially allows closer inspection of any post-treatment temporal response, the number of observations available for analysis within any given 5-yr period becomes limited and this decreases the ability to statistically detect changes in large peakflows, even if such changes truly exist. While using all post-treatment events in our analysis allows us to detect change when subdividing the record cannot (e.g. Jones and Grant (1996)'s analysis did not detect change in nine of eleven 5 -yr post-treatment periods for Watersheds 1 and 3), the magnitude of change will be biased by the normal process of forest regrowth and the resulting decay in the treatment response.

Jones and Grant (1996) chose to use a "difference variable" (suggested by Eberhardt and Thomas, 1991) for the majority of their hydrologic analyses, in particular, "difference in peakflow" and "difference in $\log$ (peakflow)". While a "difference variable" may have certain desirable statistical properties, it can be a difficult variable to interpret because it is dissociated from peakflow magnitude. In the reanalysis by Thomas and Megahan (1998) and the analysis of the modified data sets reported here, peakflow per unit area was used as the dependent variable because there is a broad base of hydrologic experience and research results associated with such variables. For example, we know that a frequency distribution of peakflows generally results in an extreme value distribution. Given a peakflow magnitude, an associated recurrence interval, and the conceptual model of the variable source area (e.g. Hewlett and Hibbert, 1967), we can place the event within a framework of understanding regarding how small watersheds and large basins function. Similarly, we can conceptually address management effects on peakflows (e.g. direction and magnitude of change) in relation to event size. Conversely, the "difference variable," because of its uncoupling with flow magnitude, carries with it no background knowledge or understanding regarding hydrologic processes. Furthermore, the differencing operation creates a new random variable that is difficult to interpret from a physical perspective, even when grouped by flow categories.

Regression analysis of paired watershed data has been a widely used statistical method for water yields, peakflows, sediment yields, and other hydrologic response variables (e.g., Harris, 1977; Beschta, 1978; Wright et al., 1990; Hicks et al., 1991). Our presentation of regression results with accompanying scattergrams, as with Thomas and Megahan (1998) not only reveals the general character of the data sets but also how well a regression relationship represents the data over the entire range of observations.

The results of our analyses indicate that peakflow increases for 0.4- to 5-yr return period events have occurred on small watersheds as a result of clearcut silviculture and the accompanying effects of roads and broadcast slash burning as practiced in the mid-1960s. However, results also indicate that peakflow increases are not evident for events greater than a 5-yr return interval for Watersheds 1 and 3. These results are generally consistent with the analytical results of Jones and Grant (1996), Thomas and Megahan (1998). However, the written conclusions presented by Jones and Grant (1996), indicating that “... the entire population of peak discharges is shifted upward by clear-cutting and roads" and "...we see no reason to expect the biggest storms to behave differently from the rest of the population" is not in agreement with either their analysis or the results of this study.

We did not find strong evidence for peakflow increases on large basins. Statistical significance $(P<$ 0.05 ) in only half the cases examined, a negative sign in the case of one of the regressions coefficients (indicating a decrease in peakflows with harvest), and weak explanation ( $r^{2}$ of 1-7\%) regarding changes in peakflow associated with the treatment variable for significant regressions does not constitute strong 
evidence of peakflow increases in the data records. This conclusion is in general agreement with the results of Thomas and Megahan (1998), although we suggest that the regression model used here is more consistent with the small watershed results than that used by Thomas and Megahan (1998).

\section{Concluding remarks}

We have focused our analysis on the large peakflow events from the three small watersheds and six large basins in the western Oregon Cascades (USA). We have done so because it is often these large events, as indicated earlier, that are important from a variety of ecological concerns (fisheries habitat, water quality, riparian vegetation), physical processes (sediment transport, channel adjustments), engineering needs (road drainage, culvert and bridge installations), and socioeconomic reasons.

Federal land management agencies in the Pacific Northwest are expending large sums of money to alter and obliterate roads on forested watersheds, partially because of concerns about forestry related peakflow increases. In other instances, both federal and private landowners are undertaking costly road drainage and culvert upgrades because of concerns about potential increases in large peakflows following harvesting. In yet other instances, road construction and harvesting are not occurring because, as suggested by the conclusions of Jones and Grant (1996), any small-watershed peakflow increases might be cumulatively greater at the large-basin scale. While forest roads may represent an important issue in mountainous terrain (e.g. slope stability, surface erosion), the analysis by Thomas and Megahan (1998) of the identical peakflow data sets used by Jones and Grant (1996) and our analysis of modified peakflow data sets for the same small watersheds do not support the concept that relatively large peakflows are increased by forest practices. Similarly, our results, and those of Thomas and Megahan (1998), do not support the large percentage increases in peakflows that Jones and Grant (1996) project for large basins.

Major differences in interpretations of results exist between those reported by Jones and Grant (1996) relative to those presented in subsequent analyses by
Thomas and Megahan (1998) and those presented herein. Many of these differences are not trivial and are perhaps unexpected given that we used the same data sets (except for our modifications to improve data quality). While some disparities in interpretation are obviously tied to differences in data quality and analytical methods, perhaps the most important differences are those that occur when conclusions were developed that went beyond the analytical results. We encourage interested readers to critically review each of these publications before forming conclusions.

An improved understanding of rainfall/runoff relationships for mountain watersheds will continue to challenge hydrologic researchers. This is particularly the case for extreme events such as peakflows where we often have the greatest difficulty in analytically deciphering potential changes associated with land use activities (road building, harvesting, site preparation). As Thomas and Megahan (1998, p. 3402) indicate: "Given the complex nature of the effects of forest cutting and roads on streamflow, it is not surprising that the literature provides mixed messages about peak flow responses...". At the small watershed scale, long-term monitoring of flows and repeated watershed experiments distributed across mountainous terrain is a continuing research need in order to sample the widely recognized temporal and spatial variability associated with mountain watersheds, their land uses, and their input functions (i.e. precipitation, snowmelt). While there are many watershed functions that are yet to be deciphered, and the use of long-term paired watershed studies (with control watersheds) and replicated watershed treatments has provided important insights into a wide range of hydrologic responses following treatment, it does not appear that the hypothesis of large increases in flood-size peakflows as a result of past and current forest land management practices should rank high on the list of future research questions.

For large basins, the desire to evaluate potential peakflow changes represents an even greater analytical challenge. The temporal and spatial distribution of precipitation and snowmelt inputs, the spatial heterogenity of basin characteristics (e.g. soils, geology, topography), gauging stations that are not of research caliber (e.g. utilize natural channels for control 
sections), and the temporal and spatial variability of land uses, coupled with the fact that only a small portion of a particular large basin will experience a land use practice in any given year, suggests that analyses of large basin data are seldom likely to be a fruitful means of deciphering potential changes in peakflows associated with forest practices.

While the analyses presented in this study are specific to the western Cascades of Oregon, the issues and concerns are likely representative of those faced by researchers elsewhere when attempting to decipher the effects of management activities on hydrologic responses for small watersheds and large basins. We trust that the discussion herein provided important insights as to the complexity and importance of some of these issues.

\section{Acknowledgements}

We are indebted to Jones and Grant for supplying us with electronic copies of their basic data. Without their cooperation, this retrospective analysis could not have been undertaken. We appreciate the cooperation of the Forest Science Department, Oregon State University, for providing additional information regarding the H.J. Andrews Experimental Watersheds from their Data Bank and the USGS Water Resources Division in Portland, Oregon, for their assistance with historical river flow records. We also appreciate the significant contributions of several reviewers; however, the conclusions presented herein are the sole responsibility of the authors.

\section{References}

Beschta, R.L., 1978. Long-term patterns of sediment production following road construction and logging in the Oregon Coast Range. Water Resour. Res. 14, 1011-1016.

Blaisdell, F.W., 1944. Discussion of: conformity between model and prototype. A Symposium. Trans. Am. Soc. Civil Engineers $109,157-166$.

Branson, F.A., Gifford, G.F., Renard, K.B., Hadley, R.F., 1981. Rangeland Hydrology, Soc. Rng. Mgmt., Rng. Sci. Ser., 1, Kendall/Hunt, Dubuque, IA.

Brooks, K.N., Ffolliott, P.F., Gregersen, H.M., Thames, J.L., 1991. Hydrology and the Management of Watersheds, Iowa State University Press, Ames, IA.

Dalrymple, T., 1953. Hydrology of flow control (Section 21-1). In: Chow, V.T. (Ed.), Flood Characteristics and Flow Determina- tion, Handbook of Applied Hydrology, Part I. McGraw-Hill, New York.

Eberhardt, L.L., Thomas, J.T., 1991. Designing environmental field studies. Ecol. Monogr. 61, 53-73.

Ferguson, R.I., 1986. River loads underestimated by rating curves. Water Resour. Res. 22, 74-76.

Grant, G.E., Wolff, A.L., 1990. Long-term patterns of sediment transport after timber harvest, western Cascade mountains, Oregon, USA. In: Sediment and Water Quality in a Changing Environment: Trends and Explanation, Gentbrugge, Belgium, Intern. Assoc. Hydrol. Sci., Publ. 203, pp. 31-40.

Harr, R.D., 1980. Streamflow after patch logging in small drainages within the Bull Run Municipal Watershed, Oregon, Res. Pap. PNW-268, USDA For. Serv., Pac. Northwest For. and Range Exp. Stn., Portland, Oregon, 16pp.

Harr, R.D., McCorison, F.M., 1979. Initial effects of clearcut logging on size and timing of peak flows in a small watershed in western Oregon. Water Resour. Res. 15, 90-94.

Harr, R.D., Fredriksen, R.L., Rothacher, J., 1979. Changes in streamflow following timber harvest in southwestern Oregon, Res. Pap. PNW-249, USDA For. Serv., Pac. Northwest For. and Range Exp. Stn., Portland, Oregon, 22pp.

Harr, R.D., Levno, A., Mersereau, R., 1982. Streamflow changes after logging 130-year-old Douglas-fir in two small watersheds. Water Resour. Res. 18, 637-664.

Harris, D.D., 1977. Hydrologic changes after logging in two small Oregon coastal watersheds. USDI Geol. Surv., Water Supply Pap. 2037, 31.

Herschy, R.W., Fairbridge, R.W., 1998. Encyclopedia of Hydrology and Water Resources, Kluwer Academic, Dordrecht.

Hewlett, J.D., Hibbert, A.R., 1967. Factors affecting the response of small watersheds to precipitation in humid areas. In: Sopper, W.E., Lull, H.W. (Eds.), International Symposium on Forest Hydrology, Permagon Press, Oxford, UK.

Hicks, B.J., Beschta, R.L., Harr, R.D., 1991. Long-term changes in streamflow following logging in western Oregon and associated fisheries implications. Water Resour. Bull. 27, 217-226.

Hirsch, R.M., Helsel, D.R., Cohn, T.A., Gilroy, E.J., 1993. Statistical analysis of hydrologic data (Chapter 17). In: Maidment, D.R. (Ed.), Handbook of Hydrology, McGrawHill, New York.

Jones, J.A., Grant, G.E., 1996. Peak flow responses to clear-cutting and roads in small and large basins, western Cascades, Oregon. Water Resour. Res. 32, 959-974.

Leopold, L.B., Wolman, M.G., Miller, J.P., 1964. Fluvial Processes in Geomorpholgy, Freeman, San Francisco, CA.

Mosley, M.P., 1981. Semi-determinate hydraulic geometry of river channels, South Island, New Zealand. Earth Surface Processes and Landforms 6, 127-137.

Nolan, K.M., Lisle, T.M., Kelsey, H.M., 1987. Bankfull discharge and sediment transport in northwestern California. In: R.L. Beschta, T. Blinn, G.E. Grant, G.G. Ice, F.J. Swanson (Eds.), Erosion and Sedimentation in the Pacific Rim, Intern. Assoc. Hydro. Sci. Publ. No. 165.

Oregon Department of Forestry, 1994. Forest practices water protection rules, Divisions $24 \& 57$. Oreg. Department of Forestry, Salem, Oregon. 
Richards, K., 1982. Rivers: Form and Process in Alluvial Channels, Methuen, New York.

Rothacher, J., 1973. Does harvest in west slope Douglas-fir increase peak flow in small forest streams? Res. Pap. PNW-163, 13.

Rothacher, J., Dyrness, C.T., Fredriksen, R.L., 1967. Hydrologic and related characteristics of three small watersheds in the Oregon Cascades. USDA For. Serv., Pac. Northwest For. and Range Exp. Stn., Portland, Oregon.

Surfleet, C., 1997. Precipitation characteristics for landslide hazard assessment in the central Oregon Coast Range. MS Thesis, Oregan State University, Corvallis, Oregon, 94pp.
Thomas, R.B., Megahan, W.F., 1998. Peak flow responses to clearcutting and roads in small and large basins, western Cascades, Oregon: a second opinion. Water Resour. Res. 34, 3393-3403.

Washington Forest Practices Board, 1995. Washington Forest Practices. Forest Practices Division, Departemnt of National Resources, Olympia, WA.

Wright, K.A., Sendek, K.H., Rice, R.M., Thomas, R.B., 1990. Logging effects on streamflow: Storm runoff at Caspar Creek in northwestern California. Water Resour. Res. 26, 1657-1667.

Ziemer, R.R., 1998. Flooding and Streamflows.USDA Forest Service General Technical Report PSW-GTR-168, pp. 15-24. 